\title{
STRESS ANALYSIS IN AL BASED COMPOSITES DEPENDING ON JOINING QUALITY
}

\author{
N. Sinan Köksal, Mehmet Alkan \\ Department of Mechanical Engineering, Celal Bayar University, 45140 Muradiye, \\ Manisa, Turkey, sinan.koksal@bayar.edu.tr
}

\begin{abstract}
It is essential that joints in the design of aluminium based materials be safe and at the desired strength. Specific methods are to be used in welding of these materials. Brazing, that assures joining without changing the material properties, is widely used for this purpose. In this method, quality joining can be achieved, provided the parameters are set up accurately. In this study, joining characteristics of aluminium based composite materials widely used in automotive industry are investigated in detail. Solid models of the parts manufactured by brazing are created using Solidworks software. Hydrostatic loading similar to the real working conditions is applied to these models and stress analysis is performed using ANSYS software. In the samples, joining regions are $2 \mathrm{~mm}$ and $2,83 \mathrm{~mm}$ in length; and stress distributions are investigated in three groups assuming full, $70 \%$ and $50 \%$ joining. Stresses arising from loading in the model are below the damage inducing level, but the shape and the length of the joining region are observed to be significant in stress development.
\end{abstract}

Key Words- Composites, stress analysis, joining region.

\section{INTRODUCTION}

Aluminium is used in industry in an ever increasing rate, mostly in the freight and passenger compartments, in the construction of the ship hull, in the propellers, radiators and engine parts of land, air and sea vehicles because of its properties such as lightweight, high thermal conductivity and that it can be alloyed with other elements. It is also used in the food industry because of its lightweight, impact-resistance and rapid cooling properties and because it can be recycled. Also, the capacity of the bridges can be increased by using aluminium as a structural element at deck while increasing the useful load-carrying capacity, and decreasing the weight of dead load (the weight of the bridge itself). When compared with other lightweight construction materials having advantageous weight/strength ratio, aluminium has considerably high corrosion resistance. Because of these features, maintenance costs reduce with increasing useful life of the bridges.

Composite materials are used particularly when high mechanical properties are desired from structures. In this way, a lighter structure and a higher weight/strength ratio is obtained. It is important that these materials, which consist of several different materials and structures, are in accordance with the desired quality of the produced composite materials. Moreover, the stress-strain characteristics and deformation states are more complicated than the metal structures. The defects in composite structure during production have negative effects on the life-time and working conditions. On the other hand, the theoretical limit values cannot be obtained by calculations and it is often 
difficult to know whether or not damage will occur and to estimate the location and degree of the damage.

Another method widely used in manufacturing honeycomb structures is the corrugation method (Figure 1). This method is preferred in manufacturing high thickness and high density honeycomb structures that will work under high temperature. In this method, a metal sheet is corrugated, and then stacked into a block. The sheets are then bonded by brazing together and the core is sliced to the desired thickness and the corrugated layers are adhesively brazed to face sheets [1-5].
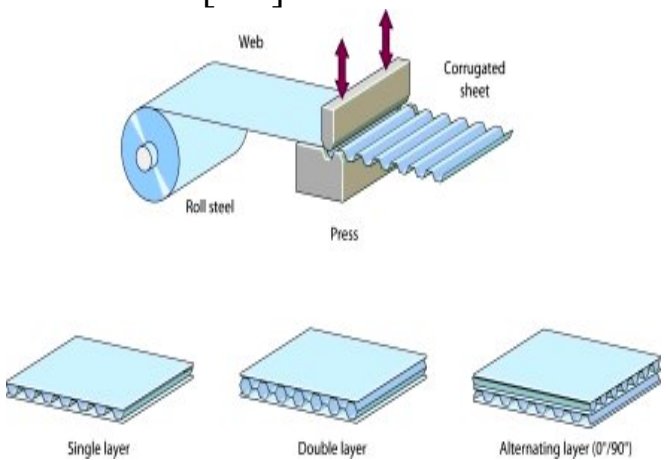

Figure 1 - Schematic illustration of the corrugation method of fabricating flat-topped prismatic cores.

Blocks obtained with corrugated ribbon plates are placed on top of each other and are kept at the pre-defined temperature for pre-defined durations. Slices are cut from the blocks in the desired thickness. The production of aluminium cells used in this study has been made by this method.

The brazing atmosphere is easily controllable in this method. Using no flux provides flexibility in the design of the connection points and no cleaning is required after brazing. Since the parts are completely heated, deformations due to thermal expansion can be minimized or eliminated. More than one joining can be brazed simultaneously by this method. Aluminium parts that have been produced in this way are used in the manufacture of the automotive and air conditioning systems, radiators, condensers, oil coolers, evaporators, air coolers.

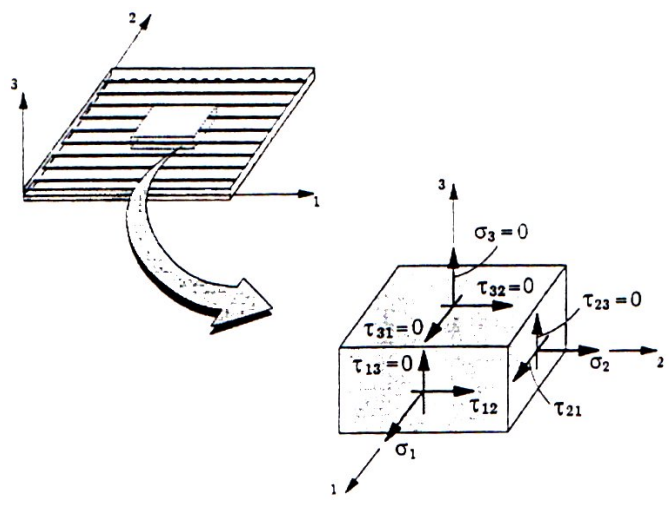

Figure $2-A$ sheet in a plane state of stress 
Engineering constants (sometimes known as technical constants) are generalized as Young's modulus, Poisson's ratio and shear modulus. These constants are measured by simple tests such as uniaxial tension test or shear test [6-9]. The slope of the stressstrain curve obtained from the test results yields the Young's modulus, which is stated as $\mathrm{E}=\sigma / \varepsilon$. (Young's moduli obtained for first, second and third directions are indicated as $E_{1}, E_{2}, E_{3}$ respectively, for the non-zero stress states). In a similar way, the Poisson's ratio expressed as $v_{12}$ is calculated by $v_{\mathrm{ij}}=-\varepsilon_{\mathrm{j}} / \varepsilon_{\mathrm{i}}$, depending on the direction. $\mathrm{G}_{12}, \mathrm{G}_{23}$, and $\mathrm{G}_{31}$ are the shear moduli in the 1-2, 2-3, and 3-1 directions, respectively. For plane stress; $\sigma_{3}=0, \tau_{23}=0, \tau_{31}=0$ and $\sigma_{1} \neq 0, \sigma_{2} \neq 0, \tau_{12} \neq 0$.

In this case, the stress-strain relations are

$$
\left[\begin{array}{l}
\varepsilon_{1} \\
\varepsilon_{2} \\
\gamma_{12}
\end{array}\right]=\left[\begin{array}{lll}
\mathrm{S}_{11} & \mathrm{~S}_{12} & 0 \\
\mathrm{~S}_{12} & \mathrm{~S}_{22} & 0 \\
0 & 0 & \mathrm{~S}_{33}
\end{array}\right]\left[\begin{array}{l}
\sigma_{1} \\
\sigma_{2} \\
\tau_{12}
\end{array}\right]
$$

or briefly,

$$
\left\{\varepsilon_{1}\right\}=[\mathrm{S}]\left\{\sigma_{1}\right\}
$$

Paying attention to the direction of the parameters, depending on the stress and displacement components, [1] is the sheet coordinates, and [S] is the compliance matrix.

$$
\mathrm{S}=\left[\begin{array}{ccc}
\frac{1}{\mathrm{E}_{1}} & -\frac{v_{21}}{\mathrm{E}_{2}} & 0 \\
-\frac{v_{21}}{\mathrm{E}_{1}} & \frac{1}{\mathrm{E}_{2}} & 0 \\
0 & 0 & \frac{1}{\mathrm{E}_{12}}
\end{array}\right]
$$

Eq. (2) can be inverted to

$$
\left\{\sigma_{1}\right\}=[\mathrm{S}]^{-1}\left\{\varepsilon_{1}\right\}
$$

or transformed into;

$$
\left\{\sigma_{1}\right\}=[\mathrm{Q}]\left\{\varepsilon_{1}\right\}
$$

where $\mathrm{Q}$ is the inverse of the compliance matrix and is called the corrected sheet stiffness matrix; it is defined in the following form by using engineering terminology;

$$
\left[\begin{array}{c}
\sigma_{1} \\
\sigma_{2} \\
\tau_{12}
\end{array}\right]=\left[\begin{array}{ccc}
\frac{E_{1}}{1-v_{12} v_{21}} & \frac{v_{12} E_{2}}{1-v_{12} v_{21}} & 0 \\
\frac{v_{12} E_{2}}{1-v_{12} v_{21}} & \frac{E_{2}}{1-v_{12} v_{21}} & 0 \\
0 & 0 & G_{12}
\end{array}\right]\left[\begin{array}{c}
\varepsilon_{1} \\
\varepsilon_{2} \\
\gamma_{12}
\end{array}\right]
$$

Honeycomb-structured composite plates, with increasing usage areas, find a place at the engineering structures today. Honeycomb composite structures are built in accordance with the purpose and place of use; parameters, such as cell size, thickness and surface coating materials, should be determined optimally. Damages occurring in the aluminium cell composite plates are as follows: honeycomb cell wall buckling around 
the load contact surface, regional cell crushing, and shear under increasing load between the cells at the intersection of the surface cover and the cells [8-15].

In this study, stress distributions that will occur under working conditions depending on the sheet - flange joint point conditions during the operation process, have been investigated. The effect of the lack of penetration on life time that may occur if the merging operation has not been done carefully is also investigated. Especially, the condition of the joint region significantly influenced the tension created by the applied load.

\section{MATERIALS AND METHODS}

\section{1. Materials}

In aluminium based composites, sheets are made up of AA5754, fins are made up of AA3003 and filler materials are made up of AA4343 materials. The chemical composition of these materials is in accordance with international standards, and the mechanical properties are given in Table 1.

Table 1 - Marterials properties

\begin{tabular}{|l|l|l|l|}
\hline & AA5754 & AA3003 & AA 4343 \\
\hline Young's Modulus & $7.1 \mathrm{e}+010 \mathrm{~Pa}$ & $7.1 \mathrm{e}+010 \mathrm{~Pa}$ & $7.1 \mathrm{e}+010 \mathrm{~Pa}$ \\
\hline Poisson Rate & 0.33 & 0.33 & 0.33 \\
\hline Density & $2770 . \mathrm{kg} / \mathrm{m}^{3}$ & $2730 . \mathrm{kg} / \mathrm{m}^{3}$ & $2770 . \mathrm{kg} / \mathrm{m}^{3}$ \\
\hline Thermal Expansion & $2.3 \mathrm{e}-0051 /{ }^{\circ} \mathrm{C}$ & $2.3 \mathrm{e}-0051 /{ }^{\circ} \mathrm{C}$ & $2.3 \mathrm{e}-0051 /{ }^{\circ} \mathrm{C}$ \\
\hline Yield Strength & $1.6 \mathrm{e}+008 \mathrm{~Pa}$ & $1.3 \mathrm{e}+008 \mathrm{~Pa}$ & $2.85 \mathrm{e}+008 \mathrm{~Pa}$ \\
\hline Tensile Strength & $3.1 \mathrm{e}+008 \mathrm{~Pa}$ & $3.1 \mathrm{e}+008 \mathrm{~Pa}$ & $3.1 \mathrm{e}+008 \mathrm{~Pa}$ \\
\hline Thermal Properties & $875.0 \mathrm{~J} / \mathrm{kg} \cdot{ }^{\circ} \mathrm{C}$ & $875.0 \mathrm{~J} / \mathrm{kg} \cdot{ }^{\circ} \mathrm{C}$ & $875.0 \mathrm{~J} / \mathrm{kg} \cdot{ }^{\circ} \mathrm{C}$ \\
\hline
\end{tabular}

These materials are combined with stiff brazing in controlled CAB (controlled atmosphere brazing) furnace (Figure 3). The composites joined in this way have become convenient for use.

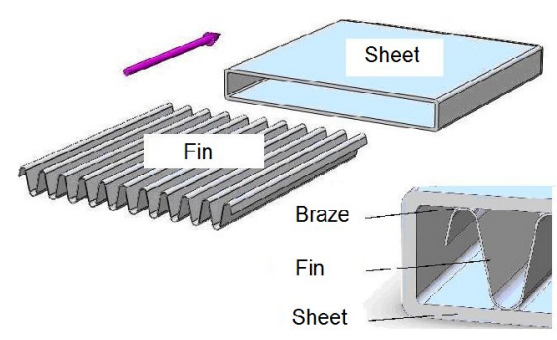

Figure 3- Sheet, fin and braze region.

\section{2. Modeling}

Solid model samples created by computer with using Solidworks are then transferred to ANSYS V11 and simulated under environmental working stresses. 
Brazed region at the contact of plate and fins were chosen to have two different radius as 0.25 and $0.50 \mathrm{~mm}$. The shape of the brazed area depends on parameters such as the width of brazing region, the amount of material used, brazing gap and oven temperature. Each of these variables affects the quality of joining. Therefore, these parameters showing a wide range of process variation should be optimized.

In this study, analysis of joining parameter was performed to show the change of location and amount of merger due to the incompliance of joining parameters during production of composites. While solid models are designed, the amount of filler material between the fins and plate were assumed full, $70 \%$ and $50 \%$ for each combination (Figure 4 - Figure 6).
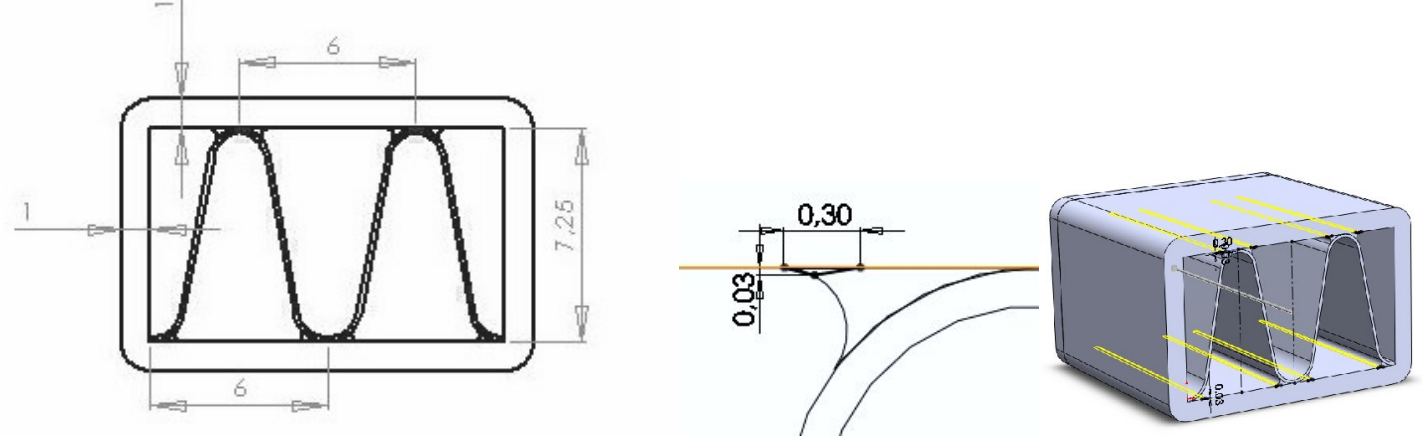

Figure 4- The dimensions of the unit cell. Figure 5- In case of unjoined dimensions.

The calculations are made according to the specified dimensions in the model and accepted measures are shown in Figure 5, for different rates due to non-union status. For non-union status shown at Figure 6, solutions have been made assuming the braze surface of the fins in contact as $\mathrm{R}=0.25 \mathrm{~mm}$,

\begin{tabular}{|c|c|c|}
\hline Brazing zone (mm) & & Contact boundary (mm) \\
\hline fully jointed & & 2,48 \\
\hline $\begin{array}{c}30 \% \text { disjointed from } \\
\text { outside }\end{array}$ & 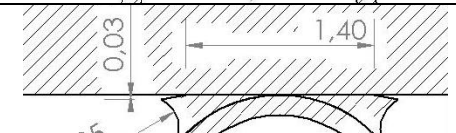 & 2,24 \\
\hline $\begin{array}{l}30 \% \text { disjointed from } \\
\text { inside }\end{array}$ & & 1,87 \\
\hline $\begin{array}{l}50 \% \text { disjointed from } \\
\text { outside }\end{array}$ & 11,0 & 2,17 \\
\hline
\end{tabular}

Figure 6- Joint formations for $\mathrm{R}=0.25 \mathrm{~mm}$ in brazing region 
Non-union status shown at Figure 7, for acceptable solutions have been made with accept the brazing surface of the fins in contact assumed $\mathrm{R}=0.5 \mathrm{~mm}$

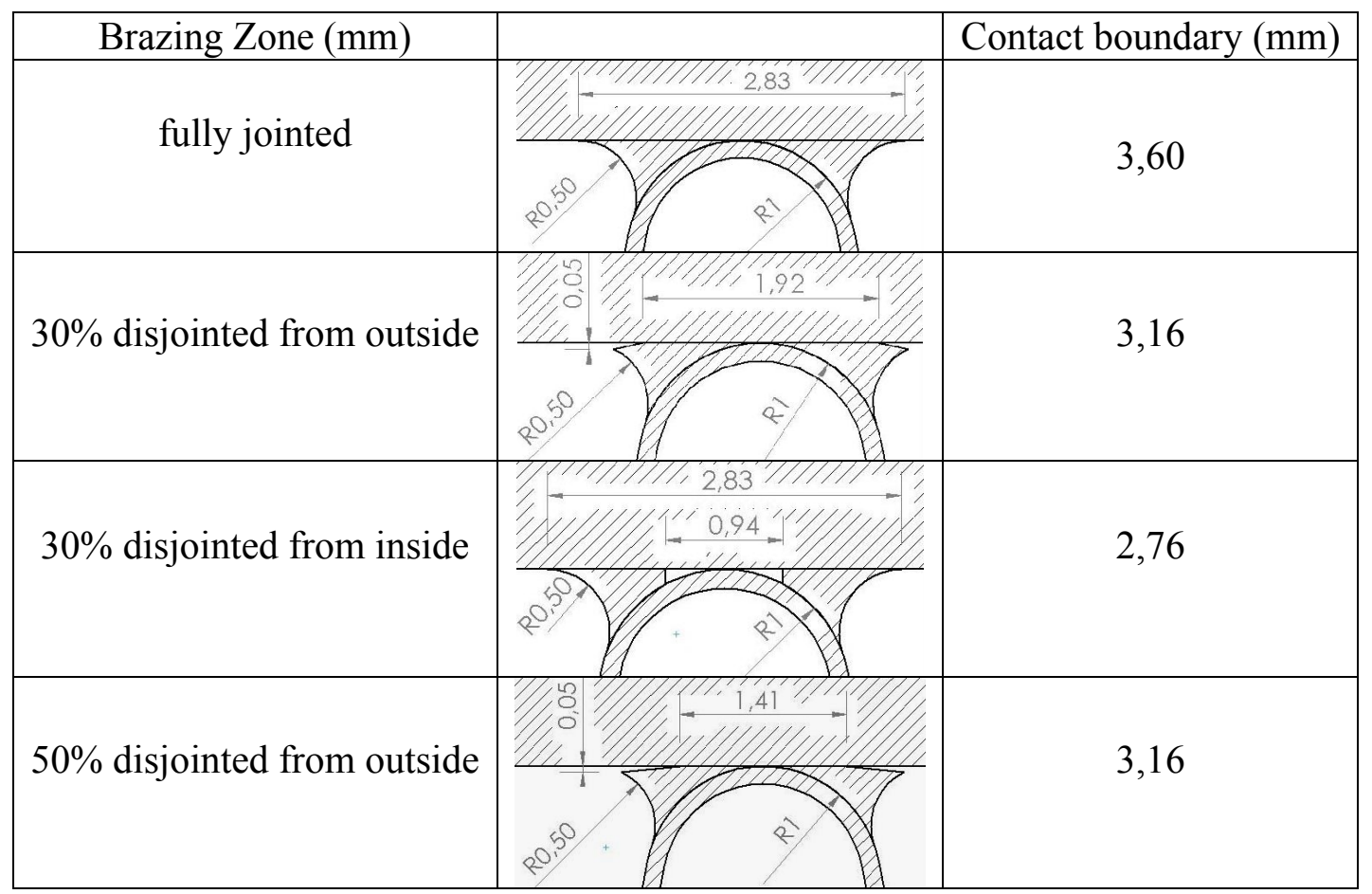

Figure 7- Joint formations for $\mathrm{R}=0.5 \mathrm{~mm}$ in brazing region

\subsection{Stress Analysis}

The specifications of materials are given in Table 1 - Table 3. For each case, the stresses caused by the loading were obtained individually for the plate, for braze + fins and for the brazing regions. The results of the analysis made in this way are given in Figure 8.
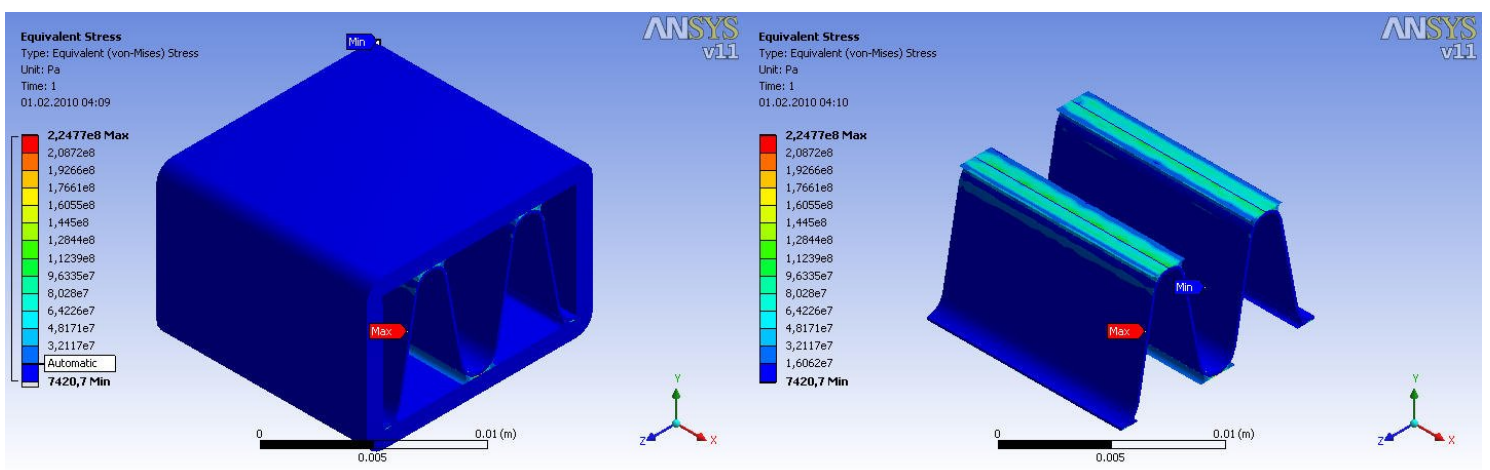


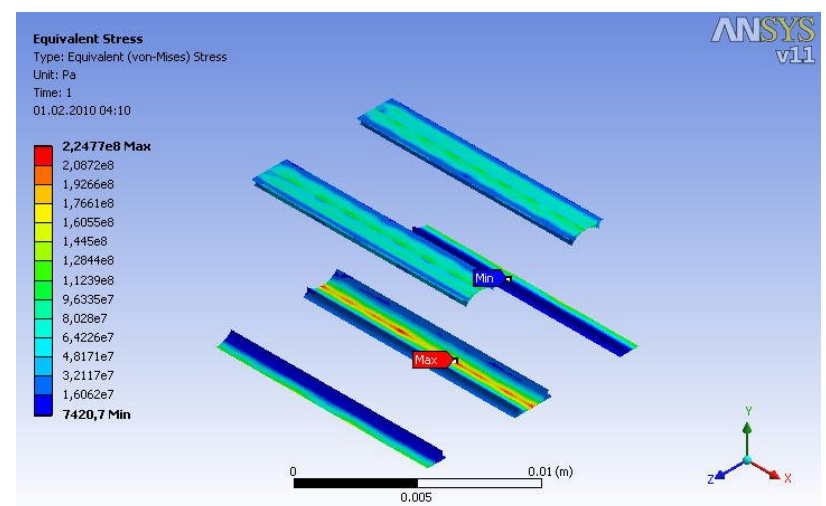

Figure 8 - Stress values and stress distributions at brazing region obtained by ANSYS.

Different types of failure criteria have been used for failure design of composite laminates. In general, the failure criteria are categorized into two: independent and interactive criterion. An independent criterion, such as maximum stress, maximum strain, is simple to apply and more significantly, tells the mode of failure, but it neglects the effect of stress interactions. For each case, the regions of maximum stress occur and the values have been obtained by the maximum stress theory and are given in Table 2.

Table 2 - Stresses in joining zone.

\begin{tabular}{|l|l|c|}
\hline & Disjoint Rate & Max. Strength (MPa) \\
\hline \multirow{4}{*}{$\mathrm{R}=0.25$} & $0 \%$ & 224.77 \\
\cline { 2 - 3 } & $30 \%$ & 214.76 \\
\cline { 2 - 3 } & $30 \%$ (outside) & 280.28 \\
\cline { 2 - 3 } & $50 \%$ & 230.66 \\
\hline \multirow{5}{*}{$\mathrm{R}=0.5$} & $0 \%$ & 211.00 \\
\cline { 2 - 3 } & $30 \%$ & 255.91 \\
\cline { 2 - 3 } & $30 \%$ (inside) & 93.18 \\
\cline { 2 - 3 } & $50 \%$ & 211.55 \\
\hline
\end{tabular}

Along the length of the unit where the maximum stress occurs and the value is examined from a different perspective, the values obtained for fins+braze are shown in Figure 9.

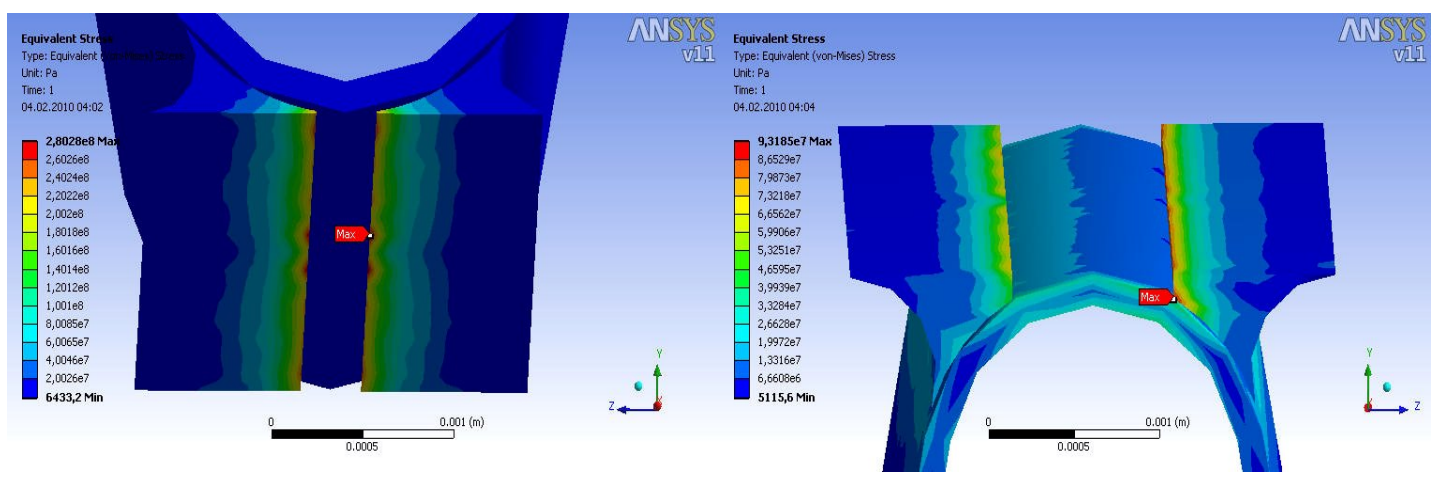

Figure 9 - Stress values and stress distributions at fins + brazing region obtained by ANSYS. 
According to this loading state, braze-fin contact length is found to be significant. For values $\mathrm{R}=0.5$ and in $30 \%$ internally disconnection case, minimum stress were obtained. Yield stresses, depending on the size of the contact surface have been forwarded to the plate.

\section{CONCLUSIONS}

At composite production, effects of combined area properties on the life time and efficiency have been determined.

Depending on the radius of the combined region, changes (at the contact circumference) are examined due to continuity less than $30 \%$ and $50 \%$ in transition zone.

According to the results of ANSYS stress analysis, stress values due to applied load are found to be below the critical value of the material, i.e. safe.

The variation in the contact boundary length, as shown in the figures, has been effective on stress values. The contact boundaries at interior sections do not affect the results significantly.

The location of the disjoined region -either the braze is near the fin (internal) or the braze is away from the fins (outside) - affects stress values due to the applied load.

\section{REFERENCES}

1. M.A. Hazizan and W.J. Cantwell, The low velocity impact response of an aluminium honeycomb sandwich structure. Composites: Part, B, 34(8), 679-687, 2003.

2. J.K., Paik, K. Anil, A.K. Thayamballi, and Kim, G.S. The strength characteristics of aluminum honeycomb sandwich panels, Thin-Walled Structures, 35(3), 205-231, 1999.

3. M.O. Kaman, M.Y. Solmaz, K. Turan, Experimental and Numerical Analysis of Critical Buckling Load of Honeycomb Sandwich Panels, Journal of Composite 44 (21), 2010.

4. Y.M. Jen, C.W. Ko and H.B. Lin, Effect of the amount of adhesive on the bending fatigue strength of adhesively bonded aluminium honeycomb sandwich beams, International Journal of Fatigue, 31(3), 455-462, 2009.

5. M. He and W., Hu, A study on composite honeycomb sandwich panel structure, M. Materials and Design, 29(3), 709-713. 2008.

6. C. Ataş, A cost effective method for impact induced damage assessment of laminated plates, Science and Engineering of Composite Materials, 15, 31- 49. 2008.

7. G.G. Galletti, C. Vinquistand and O.S. Es-Said, Theoretical design and analysis of a honeycomb panel sandwich structure loaded in pure bending, Engineering Failure Analysis, 15(5), 555-562. 2008

8. A.R. Othman and D.C. Barton, Failure initiation and propagation characteristics of honeycomb sandwich composites, Composite Structures, 85(2), 126-138, 2008.

9. I.M. Daniel and J.L. Abot, , Fabrication, testing and analysis of composite sandwich beams, Composites Science and Technology, 60(12-13), 2455-2463, 2000.

10. P. Bunyawanichakul, B. Castanié and J.J. Barrau, Non-linear finite element analysis of inserts in composite sandwich structures, Composites: Part B, 39(7-8), 1077-1092, 2008. 
11. L. Aktay, A.F. Johnson and B.H. Kroplin, Numerical modelling of honeycomb core crush behaviour, Engineering Fracture Mechanics, 75(9), 2616-2630, 2008.

12. S. Belouettar, A. Abbadi, Z.Azari, R.Belouettar and P. Freres, Experimental investigation of static and fatigue behaviour of composites honeycomb materials using four point bending tests, Composite Structures, 87(3), 265-273, 2009.

13. T. Fiedler and A. Ochsner, Experimental analysis of the flexural properties of sandwich panels with cellular core materials, Materialwissenschaft und Werkstofftechnik, 39(2), 121-124, 2008.

15. Y.P. Siow and V.P.W. Shim, An experimental study of low velocity impact damage in woven fiber composites, Journal of Composite Materials, 32, 1178-1202, 1998.

16. M. He and W. Hu, A study on composite honeycomb sandwich panel structure, Materials and Design, 29(3), 709-713, 2008. 